\section{KẾT LUÂN}

Trầm cảm xuất hiên với tỉ lệ tương đối cao ở những bệnh nhân có RLCD, người bệnh có rối loạn cương dương cần được sàng lọc các triệu chứng của trầm cảm, nhất là người bệnh có độ tuổi dưới 40 tuổi.

\section{TÀI LIÊU THAM KHẢO}

1. S. Nimesh, R. Tomar, M. Kumar, N. Tyagi, and P. K. Shukla, "Erectile Dysfunction: An Update," Adv. Medical, 'Dent. Heal. Sci., vol. 2, no. 1, pp. 04-07, 2019, doi: 10.5530/amdhs.2019.1.3.

2. H. A. Feldman, I. Goldstein, D. G. Hatzichristou, R. J. Krane, and J. B. McKinlay, "Impotence and its medical and psychosocial correlates: results of the Massachusetts Male Aging Study.," J. Urol., vol. 151 , no. 1 , pp. 54-61, Jan. 1994, doi: $10.1016 / \mathrm{s} 0022-5347(17) 34871-1$.
3. D. M. Lee et al., "Cohort profile: The european male ageing study," Int. J. Epidemiol., vol. 42, no. 2, pp. 391-401, 2013, doi: 10.1093/ije/dyr234.

4. G. Rastrelli and M. Maggi, "Erectile dysfunction in fit and healthy young men: Psychological or pathological?," Translational Andrology and Urology, vol. 6, no. 1. AME Publishing Company, pp. 79-90, 2017, doi: 10.21037/tau.2016.09.06.

5. J. Y. Jeong, S. K. Lee, Y. W. Kang, S. N. Jang, Y. J. Choi, and D. H. Kim, "Relationship between ED and depression among middle-aged and elderly men in Korea: Hallym aging study," Int. J. Impot. Res., vol. 23, no. 5, pp. 227-234, 2011, doi: 10.1038/ijir.2011.32.

6. G. S. Malhi and J. J. Mann, "Depression," Lancet, vol. 392, no. 10161, pp. 2299-2312, 2018, doi: 10.1016/S0140-6736(18)31948-2.

7. H. I. Sadock, B. J., Sadock, V. A., Ruiz, P., \& Kaplan, Kaplan and Sadock's comprehensive textbook of psychiatry, 10th ed. Wolters Kluwer., 2017.

\title{
NGHIÊN CỨU ĐĂC ĐIỂM LÂM SÀNG VÀ HÌNH ẢNH SIÊU ÂM, HìnH ẢNH CộNG HƯởNG TỪ CỦA LAC NộI MẠC TRONG CƠ TỬ CUNG
}

\section{TÓM TẮT}

Mục tiêu: Mô tả các đặc điểm lâm sàng, hình ảnh trên siêu âm qua âm đạo (TVS) và cộng hưởng từ của lạc nội mạc trong cơ tử cung (adenomyosis). Phương pháp nghiên cứu: 31 bệnh nhân nữ đi khám phụ khoa hoắc vô sinh do có triêuu chứng lâm sàng nghi ngờ LNMTCTC, được siêu âm qua đường âm đạo, chụp cộng hưởng từ tử cung tại bệnh viện Đại học Y Hà Nội và bệnh viện đa khoa Tâm Anh và đồng ý tham gia nghiên cứu. Kết quả: Có 31 bênh nhân vớituổi trung bình là 42,03 $\pm 6,4$ tuổi. Triệu chứng đau bunng kinhchiếm khoảng $90.3 \%$. Có $27 \%$ trường hợp có hình ảnh LNMTCTC trên TVS. Hình ảnh trên siêu âm bao gồm: nhiều nang nhỏ trong lớp cơ tử cung chiếm 83,9\%, các đảo tăng âm trong cơ tử cung chiếm 83,9\%, đường hoặc chồi tăng âm dưới nội mạc tử cung là $32,3 \%$, hình ảnh bóng rẻ quat là $78,1 \%$, vùng nối không đều chiếm $12,9 \%$ và hình ảnh tưới máu lan tỏa trên siêu âm Doppler là $80,7 \%$. Vi trí của LNMTCTC xuất hiện ở thành trước $(37,0 \%)$, thành sau $(81,5 \%)$, thành phải $(40,7 \%)$, thành trái $(48,2 \%)$ và đáy tư cung $(63,0 \%)$. LNMTCTC khu trú chiếm $14,81 \%$, lan tỏa chiếm $66,7 \%$ và u tuyến cơ

${ }^{1}$ Trường Đại học Y Hà nội

²Bênh viện đa khoa Tâm Anh

${ }^{3}$ Bênh viện Đại Học Y Hà nội

Chị trách nhiệm chính: Hoàng Đình Âu

Email: hoangdinhau@gmail.com

Ngày nhận bài: 23.6.2021

Ngày phản biên khoa họ: 19.8.2021

Ngày duyệt bài: 25.8.2021
Đặng Hoàng Hà ${ }^{1}$, Lê Hoàng ${ }^{2}$, Hoàng Đình $\hat{A ̂ u}^{3}$

(adenomyoma) chiếm 18,5\%. Sự xuất hiện của nang trong LNMTCTC chiếm $100 \%$. Tốn thương nằm ở vị trí lớp trongcơ tử cung $(77,8 \%)$, lớp giữa cơ tử cung $(96,3 \%)$ và lớp ngoài cơ tử cung $(88,9 \%)$. Mức đô của bệnh mức độ nhe chiếm 22,2\%; mức độ vừa là 33,3\% và̀ năng chiếm $44,5 \%$. Đường kính trung bình của LNMTCTC là $41,1 \pm 15 \mathrm{~mm}$. Đặc điểm trên hình ảnh MRI: tín hiêu cường đô hỗn hợp trên T1W là 64,5\%, trên $\mathrm{T} 2 \mathrm{~W}$ là $48,4 \%$, tăng tín hiệu trên T1FS là $9,7 \%$ liên quan với tình trạng chảy máu. Độ dày trung bình của vùng nối là $22,3 \pm 17,5 \mathrm{~mm}$. Các bệnh vùng chậu đi kèm với LNMTCTC: u xơ tử cung $(32,3 \%)$, u nang buồng trứng đơn thuần $(9,7 \%)$, nang lạc nội mạc tư cung trong buồng trứng $(32,3 \%)$, u quái buồng trứng $(6,5 \%)$. Kết luâan: Trong các trường hợp nghi ngờ LNMTCTC trên lâm sàng, siêu âm đường âm đaolà phương tiện chẩn đoán được lựa chọn đầu tiên. MRI có thể được xem xét khi TVŚ không thể đánh giá đước.MRI là phương phápchẩn đoán chính xác cho LNMTCTC, cho phép phát hiện các bênh lý vùng chậu liên quan. Đặc điểm quan trọng nhất trên MRI trong chẩn đoán là xác định độ dày của vùng nối trên $12 \mathrm{~mm}$.

Tư khóa: lac nôi mac trong cơ tử cung, hình ảnh cộng hưởng từ, siêu âm qua đường âm đạo

\section{SUMMARY}

\section{RESEARCH CLINICAL CHARACTERISTICS AND IMAGE FEATURES OF ULTRASOUND} AND MRI OF ADENOMYOSIS

Objective: Describle the clinical symptoms, transvaginal ultrasound (TVS) and MRI features of adenomyosis. Methods: Thirty - one females patients was suspecteduterine adenomyosis in clinic, diagnosed 
using ultrasound and MRIat Hanoi Medical University Hospital and General Hospital Tam Anh, were included in this prospective study. We conducted describing and analyzing all imaging feature, which determined adenomyosis from 06/2020 to 09/2021. Results: Mean ageof $42.03 \pm 6.4$. Abdominal pain during menstrual periode around $90.3 \%$. The morphological uterine sonographic include myometrial cysts was $83.8 \%$, hyperechogenic islands in the myometrium was $83.9 \%$, echogenic subendometrial lines and buds was $32.3 \%$, fan-shaped shadowing was $78.1 \%$, irregular junctional zone account for $12.9 \%$ and translesional vascularity on color Doppler ultrasound was $80.65 \%$, poor definition of the endomyometrial junction was $38.7 \%$. There are $27 \%$ ofcases with adenomyosis on TVS. The location of the adenomyosis is present in anterior (37.0 \%), posterior (81.5\%), lateral right $(40.7 \%)$, lateral left $(48.2 \%)$ and fundal $(63.0 \%)$. Adenomyosis are focal accounts for $14.8 \%$, diffuse account for $66.7 \%$ and adenomymoma for $18.5 \%$. Presence of cysts in adenomyosis occupies $100 \%$. Lesions arelocated on the inner myometrium $(77.8 \%)$, the middle myometrium $(96.3 \%)$ and the outer myometrium (88.9\%). The extent of the disease which estimated proportion of the uterine corpus is classified as mild (22.2\%); moderate (33.3\%) and severe $(44.5 \%)$. Features on MRI imaging: mixed intensity signal on T1W was $64.5 \%$, on T2W was $48.4 \%$, hyperintenisty signal on T1FS was $9.7 \%$ correlatingwith hemorrhage. The averagethickness of the junctional zone is $22.3 \pm 17.5 \mathrm{~mm}$. Another pelvis diseases correlating with adenomyosis: fibroids $(32.3 \%)$, simple ovarian cysts $(9.7 \%)$, endometriosis ovarian $(32.3 \%)$, ovarian teratoma (6.5\%). Conclusion: In clinically suspected adenomyosis cases TVS should be favoured as the primary diagnostic tool. MRI may be considered when TVS is inconclusive. MRI represents an accurate evaluation tool for adenomyosis, allowing its diagnosis and detection of associated pathologies. The most important MR finding in making the diagnosis is thickness of the junctional zone exceeding $12 \mathrm{~mm}$.

Keywords: Adenomyosis, magnetic resonance imaging

\section{I. ĐĂT VẤN ĐỀ}

Lạc nội mạc trong cơ tử cunglà sự hiện diện của mô nội mạc tử cung có chức năng nằm bên trong lớp cơ tử cung, chịu sự chi phối của hormon theo chu kỳ kinh giống như nội mạc tử cung. Điêuu này dẫn đến hiện tượng "mắc kẹt" nghĩa là đến ngày hành kinh lớp nội mạc bề mặt bong tróc hình thành hiện tượng xuất huyết còn nôi mac trong cơ lại không thể đào thải ra ngoài dẫn đến ứ đọng, phù nề, xung huyết, phình to lớp cơ và đau vùng chậu. Lạc nội mạc trong cơ tử cung gây đau bụng kinh kéo dài, có thể dẫn đến vô sinh. Các kỹ thuật chẩn đoán hình ảnh hiện nay bao gồm siêu âm qua đường âm đạo (TVUS) và chụp cộng hưởng từ $(\mathrm{CHT})$ là hai phương pháp chẩn đoán chính xác nhằm tránh những thủ thuật xâm lấn không cần thiết cho bệnh nhân. Do đó chúng tôi tiến hành đề tài "Nghiên cứu đặc điểm lâm sàng và hình ảnh siêu âm, hinh ảnh cộng hưởng từ của lạc nội mạc trong cơ tứ cung"

\section{II. ĐỐI TƯợNG VÀ PHƯƠNG PHÁP NGHIÊN CỨU}

Nghiên cứu mô tả, tiến cứu trên 31 bệnh nhân nữ được lựa chọn vào nghiên cứu do có triệu chứng lâm sàng nghi ngờ lạc nội mạc tử cung trong cơ tử cung trên lâm sàng, đượcchẩn đoán bằng siêu âm qua đường âm đạo và cộng hưởng từ tiểu khung từ 06/2020 đến 09/2021. Bệnh nhân được loại trừ nếu không chụp được cộng hưởng từ tiểu khung (do vật kim loại gấy nhiểu...) hoặc không đồng ý tham gia nghiên cứu.

Protocol chụp công hưởng từ tiểu khung với các chuỗi xung T2W sagittal, coronal và axial, T1W không xoá mõ axial, DWI, T1WFS có tiêm đối quang từ.

\section{KẾT QUẢ NGHIÊN CứU}

- Đô tuổi trung bình: 42.03 ะ 6.4 tuổi

Bảng 1: Các triệu chứng lâm sàng $(N=31)$

\begin{tabular}{|c|c|c|}
\hline $\begin{array}{c}\text { Triệu chứng } \\
\text { Chảy máu tử cung bất } \\
\text { thường }\end{array}$ & $\mathbf{2 4}$ & $\mathbf{7 7 . 4}$ \\
\hline $\begin{array}{c}\text { Chảy máu kinh nguyệt nặng, } \\
\text { kéo dài }\end{array}$ & 18 & 58.1 \\
\hline $\begin{array}{c}\text { Chảy máu giữa các chu kỳ kinh } \\
\text { nguyệt }\end{array}$ & 4 & 12.9 \\
\hline Chảy máu trước kỳ kinh nguyệt & 2 & 6.4 \\
\hline Đau bụng & $\mathbf{2 8}$ & $\mathbf{9 0 . 3}$ \\
\hline Đau bụng kinh & 17 & 54.8 \\
\hline Đau khi giao hợp & 6 & 19.4 \\
\hline Đau vùng chậu mãn tính & 5 & 16.1 \\
\hline Vô sinh và sảy thai liên tiếp & $\mathbf{1 7}$ & $\mathbf{5 4 . 8}$ \\
\hline $\begin{array}{c}\text { Các triệu chứng tiết niệu và } \\
\text { đường tiêu hóa }\end{array}$ & $\mathbf{1}$ & $\mathbf{3 . 2}$ \\
\hline Khó đi tiếu & 0 & 0 \\
\hline Khó đi cầu & 1 & 3.2 \\
\hline
\end{tabular}

Nhân xét: Đau bụng kinh là triệu chứng thường gặp nhất

Bảng 2: Đặc điểm hình ảnh trên siêu âm $(N=31)$

\begin{tabular}{|c|c|c|}
\hline $\begin{array}{c}\text { Đặc điếm hình ảnh trên } \\
\text { siêu âm }\end{array}$ & $\mathbf{N}$ & $\mathbf{\%}$ \\
\hline $\begin{array}{c}\text { Hình ảnh nhiêu nang nhỏ } \\
\text { trong lớp cơ tứ cung }\end{array}$ & 26 & 83.9 \\
\hline $\begin{array}{c}\text { Hình ảnh nhiều đảo tăng âm } \\
\text { trong lớp cơ }\end{array}$ & 26 & 83.9 \\
\hline $\begin{array}{c}\text { Hình ảnh bóng rẻ quạt trong } \\
\text { lớp cơ tử cung }\end{array}$ & 25 & 78.1 \\
\hline
\end{tabular}




\begin{tabular}{|c|c|c|}
\hline $\begin{array}{c}\text { Đường tăng âm dưới nội mạc } \\
\text { tử cung }\end{array}$ & 10 & 32.3 \\
\hline $\begin{array}{c}\text { Doppler có hình ảnh tưới máu } \\
\text { lan tỏa }\end{array}$ & 25 & 80.7 \\
\hline Vùng nối không đều & 4 & 12.9 \\
\hline Gián đoạn vùng nối & 0 & 0 \\
\hline
\end{tabular}

Nhânn xét: Các dấu hiệu lạc nội mạc trong cơ tử cung thường gặp trên siêu âm bao gồm hình ảnh nhiêu nang nhỏ, đảo tăng âm, bóng rẻ quạt trong lớp cơvà tăng tưới máu trên siêu âm Doppler (đều chiếm >70\%).

Bảng 3: Bảng phân loại và mô tả lạc nội mac trong cơ tử cung tử cung trên siểu âm

\begin{tabular}{|c|c|c|c|}
\hline \multicolumn{2}{|c|}{ Đăc điếm } & $\mathbf{N}$ & $\%$ \\
\hline \multirow{2}{*}{$\begin{array}{l}\text { Sự hiện diện của } \\
\text { LNM trong cơ tư } \\
\text { cung }(\mathrm{N}=31)\end{array}$} & Có & 27 & 87.1 \\
\hline & Không & 4 & 12.9 \\
\hline \multirow{5}{*}{$\begin{array}{c}\text { Vị trí } \\
(\mathrm{N}=27)\end{array}$} & Thành trước & 10 & 37.0 \\
\hline & Thành sau & 22 & 81.5 \\
\hline & Bên phải & 11 & 40.7 \\
\hline & Bên trái & 13 & 48.2 \\
\hline & Đáy & 17 & 63.0 \\
\hline \multirow{2}{*}{$\begin{array}{c}\text { Phân } \\
\text { loạiLNMTCTC }\end{array}$} & Khu trú & 4 & 14.8 \\
\hline & Lan tỏa & 18 & 66.7 \\
\hline
\end{tabular}

\begin{tabular}{|c|c|c|c|}
\hline \multirow{2}{*}{$(\mathrm{N}=27)$} & $\begin{array}{c}\text { U tuyến cơ } \\
\text { (Adenomymoma) }\end{array}$ & 5 & 18.5 \\
\hline \multirow{2}{*}{ Nang(N=27) } & Có & 27 & 100 \\
\cline { 2 - 4 } & Không & 0 & 0 \\
\hline $\begin{array}{c}\text { Vị trí liên quan } \\
\text { đến vị trí lớp cơ } \\
\text { tử cung (N=27) }\end{array}$ & Trong & 21 & 77.8 \\
\cline { 2 - 4 } & giữa & 26 & 96.3 \\
\hline $\begin{array}{c}\text { Mức độ của } \\
\text { LNMTCTC }\end{array}$ & Ngoài & 24 & 88.9 \\
\cline { 2 - 4 }$(\mathrm{N}=27)$ & Nhẹ & 6 & 22.2 \\
\cline { 2 - 4 } & Vựa & 9 & 33.3 \\
\hline
\end{tabular}

Đường kính tối đa trung bình của lạc

nội mạc trong cơ tử cung (mm) $41.1 \pm 15.0$ $(\mathrm{N}=27)$

Nhân xét. Phân lớn bệnh nhân có tổn thương lạc nội mạc trong cơ tử cung (87.1\%), trong đó tổn thương nằm ở vị trí thành sau và đáy là chủ yếu, vị trí liên quan đến lớp cơ tử cung (giữa, trong, ngoài) có tỉ lệ gân tương đồng nhau. Phân bố lạc nội mạc trong cơ tử cung dạng lan tỏa $(66.7 \%)$ và ở mức độ nặng (44.5\%) chiếm tỉ lệ nhiêu nhất. Tất cả bệnh nhân có lạc nội mạc trong cơ tử cungđều có tổn thương dạng nang.

Bảng 4. Tín hiệu lạc nội mạc trong cơ tử cung trên các chuối xung thường quy (N=31)

Tín hiệu lạc nội mạc trong cở tử cung T1W

T1W xóa mõ

\begin{tabular}{|c|c|c|}
\hline \multicolumn{2}{|c|}{ Giảm đồng nhất } & \multicolumn{2}{|c|}{ Hôn } \\
\hline $\mathbf{N}$ & $\mathbf{\%}$ & $\mathbf{N}$ \\
\hline 19 & $61.3 \%$ & 12 \\
\hline 2 & $6.5 \%$ & 29 \\
\hline 19 & $61.3 \%$ & 12 \\
\hline
\end{tabular}
Hồn hợp Tăng đồng nhất

Nhận xét: Đa số tín hiệu LNMTCTC giảm đồng nhấttrên T1W và hồn hợp trên T2W. Nhóm tăng trên TiW xóa mõ chiếm tỉ lệ là $38.7 \%$

Bảng 5: Đặc điểm tín hiệulạc nội mạc trong cơ tử cung trên cộng hưởng từ khuếch tán

\begin{tabular}{|c|c|c|c|c|}
\hline Sự khuếch tán của LNMTCTC & \multicolumn{3}{|c|}{ Hạn chế } & \multicolumn{2}{c|}{ Không hạn chế } \\
\hline \multirow{2}{*}{ DWI b1000 } & $\mathbf{N}$ & $\mathbf{\%}$ & $\mathbf{N}$ & $\mathbf{\%}$ \\
\cline { 2 - 5 } & 2 & 6.5 & 29 & 93.5 \\
\hline
\end{tabular}

Nhận xét: Đa sốlạc nội mạc trong cơ tử cung khônghạn chế khuếch tántrên DWI b1000

Bảng 6: Bề dày của vùng chuyển tiếp ( $N=31)$

\begin{tabular}{|c|c|c|}
\hline Bề dày của vùng chuyến tiếp & $\mathbf{N}$ & $\mathbf{\%}$ \\
\hline$<8 \mathrm{~mm}$ & 10 & 32.3 \\
\hline $8-12 \mathrm{~mm}$ & 1 & 3.2 \\
\hline$>12 \mathrm{~mm}$ & 20 & 64.5 \\
\hline Bề dày trung bình $\mathbf{( m m )}$ & \multicolumn{2}{|c|}{$22.3 \pm 17.5$} \\
\hline
\end{tabular}

Nhận xét: Bề dày vùng chuyến tiếp đa số trên $12 \mathrm{~mm}$.

Bảng 7: Bệnh lí vùng chậu đi kèm với LNMTCTC trên MRI (N=31)

\begin{tabular}{|c|c|c|}
\hline Các bệnh lí vùng chậu đi kèm & $\mathbf{N}$ & $\mathbf{\%}$ \\
\hline U xơ tứ cung kèm theo & 10 & 32.3 \\
\hline Nang lạc nội mạc tử cung ở phần phụ và hoặc buồng trứng & 10 & 32.3 \\
\hline Nang âm đạo & 1 & 3.2 \\
\hline Viêm phần phụ bên phải & 1 & 3.2 \\
\hline Teratoma buồng trứng phải & 1 & 3.2 \\
\hline Teratoma buồng trứng trái & 1 & 3.2 \\
\hline Nang xuất huyết buồng trứng & 3 & 9.7 \\
\hline
\end{tabular}

Nhận xét: Nang lạc nội mạc của tử cung ở buồng trứng và UXTC là bệnh lý thường đi kèm với 


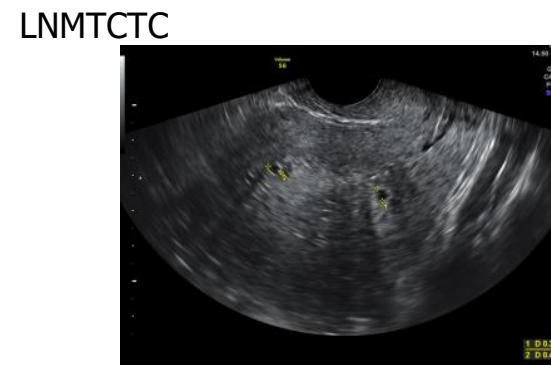

A)

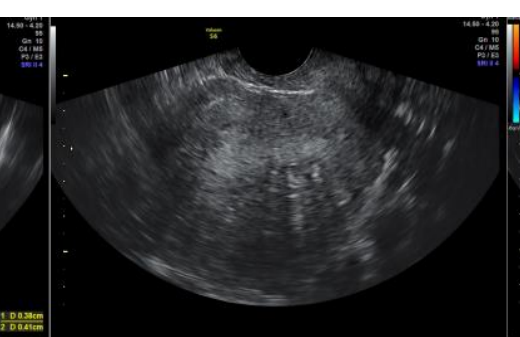

B)

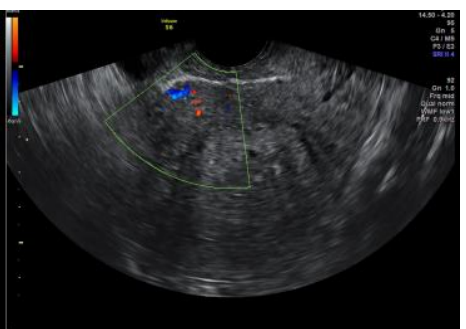

C)

Hình 1: Hình ảnh siêu âm LNMTCTC của bệnh nhân N.T.N nữ,

47 tuổi qua siêu âm đường ầm đạo

A. Nhiều nang nhỏ trong lớp cơ tử cung, ở dưới niêm mạc và có bất cân xứng thành $T C$, thành sau dày hơn thành trước. TC to hình cầu.

B. Nhiều đảo tăng âm trong cơ TC và đường tăng âm dưới nội mạc TC, gián đoạn vùng nối và có hình bóng rẻ quạt bên trong.

C. Siêu âm Doppler thấy tưới máu lan tỏa.

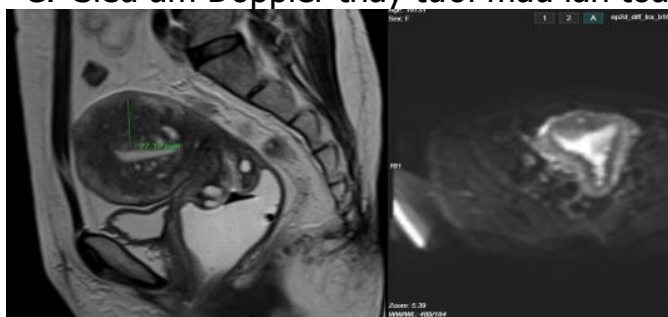

A)

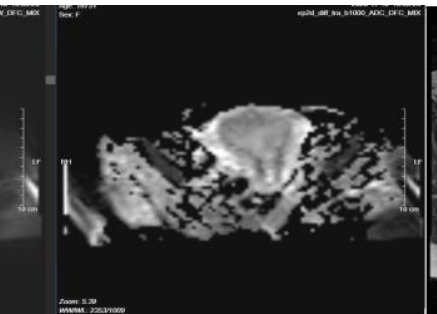

B)

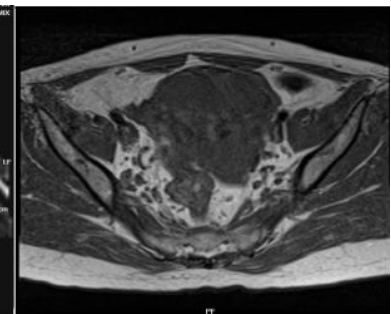

C)

A. Xung Sagittal T2W thấy hình ảnh TC to, bất cân xứng thành TC, thành sau dày hơn thành trước, bề dày vùng nối chỗ dày nhất $27 \mathrm{~mm}$, có nhiều nang nhỏ tăng tín hiệu bên trong.

B. Xung DWI và $A D C$ axial: không có hạn chế khuếch tán

C. Xung T1W axial: không thấy có hình ảnh các ổ tăng tín hiệu bên trong.

\section{BÀN LUẬN}

Trong nghiên cứu của chúng tôi, bệnh trong độ tuổi chủ yếu là nhóm tiền mãn kinh (40-60 tuổi) với tuổi trung bình là $42.03 \pm 6.4$ tuổi. Theo Parazzini ${ }^{1}$ lạc nội mạc trong cơ tử cung được xác định là một bệnh điển hình của phụ nữ trung niên (40-50 tuổi). Tuy nhiên, trong môt nghiên cứu siêu âm gần đây của ông năm 2015, hơn 30\% trường hợp ở phụ nữ từ 18 đến 30 tuối gặp lạc nội mạc trong cơ tử cung. Trong nghiên cứu tương tự của Chapron ở nhóm phu nữ dưới 42 tuổi cho thấy rằng lạc nội mạc trong cơ tử cung lan tỏa xảy ra ở $1 / 3$ đối tượng nghiên cứu $(34,6 \%)$.

Nếu chỉ dựa vào triệu chứng lâm sàng rất khó chẩn đoán xác định lạc nội mạc trong cơ tử cungvì triệu chứng lâm sàng đa dạng và có thể trùng lấp với các bênh lí khác như hội chứng ruột kích thích hay bệnh lý viêm vùng chậu. Kết quả của chúng tôi có $90.3 \%$ bệnh nhânđau bụng kinh, ngoài ra còn gặp các triệu chứng chảy máu tứ cung bất thường $(77.4 \%)$, vô sinh và sảy thai liên tiếp $(54.8 \%)$ và các triệu chứng đường tiêu hóa (3.2\%). Kết quả này cững tương tự như nghiên cứu củaStephan Gordts, trong nhóm bệnh nhân của ông đau bụng kinh là biểu hiện hay gặp nhất chiếm từ $50 \%$ đến $93,4 \%$, ${ }^{2}$ bên canh đó còn găp các triệu chứng khác nhưchảy máu tử cung bất thường, vô sinhvà các triệu chứng bàng quang, đường tiêu hóa (khó đi tiểu...).

Theo các y văn chẩn đoán hình ảnh, siêu âm qua đường âm đạo và MRI là 2 kỹ thuật không xâm lấn có thể chẩn đoán xác định lạc nội mạc trong cơ tử cung với độ nhạy và độ đặc hiệu cao. Trong một nghiên cứu tổng phân hợp với 23 bài báo (liên quan đến 2.312 phụ nữ) cho thây siêu âm qua đường âm đạo có độ nhạy là $72 \%$, độ đặc hiệu là $81 \%$, tỷ lệ khả năng dương tính là $3,7(95 \%$ CI $2,1-6,4)$ và tỷ lệ khả năng âm tính là $0,3(95 \% \mathrm{CI} 0,1-0,5)$. MRI có độ nhạy là $77 \%$, độ đặc hiệu $89 \%$, tỷ lệ khả năng dương tính là $6,5(95 \%$ CI $4,5-9,3)$ và tỷ lệ khả năng âm tính là $0,2 \%(95 \%$ CI $0,1-0,4) \cdot{ }^{3}$ Kêt quả cho thây chẩn đoán bằng MRIchính xác hơn so với SA đường 
âm đạo không những trong đánh giá vị trí, độ lan rộng của tổn thương mà còn giúp chẩn đoán phân biệt với u xơ tử cung (UXTC) trong những trường hợp khó.

Về đặc điểm lạc nội mạc trong cơ tử cung trên siêu âm qua đường âm đạo,theo đồng thuận nhóm Morphological Uterus Sonographic Assessment (MUSA) 2019, lạc nội mạc trong cơ tử cungđiển hình được mô tả với các đặc điểm sau: tử cung hình cầu, dày thành tử cung không đối xứng, nhiêu nang nhỏ trong cơ tử cung, nhiều đảo tăng âm trong cơ tử cung, bóng hình rẻ quạt, đường tăng âm dưới nội mạc tử cung, mạch máu xuyên qua tổn thương trên siêu âm Doppler, vùng nối không đều, gián đoạn vùng nối. Hội đồng thuận MUSA cũng đưa ra khuyến cáo siêu âm khảo sát lạc nội mạc trong cơ tử cungcần đánh giá qua 7 bước: bước 1 - chẩn đoán sự hiện diện của lạc nội mạc trong cơ tử cung, bước 2 - xác định vị trí lạc nội mạc trong cơ tử cungở thành trước, sau, bên trái, bên phải hay đáy tử cung, bước 3 - phân loại lạc nội mạc trong cơ tử cung(dạng khu trú, lan tóa hay hổn hợp), bước 4 - mô tả tổn thương dạng nang hay không nang; bước 5 - khảo sát mức độ xâm lấn lớp cơ tử cung đến lớp cơ trong, lớp cơ giữa, lớp cơ ngoài; bước 6 - chẩn đoán mức độ: nhẹ (tổn thương $<25 \%$ cơ tử cung), trung bình (tổn thương 25-50\% cơ tử cung), nặng (tổn thương $>50 \%$ cơ tử cung); bước 7 - đo kích thước khối tổn thương. ${ }^{4}$ Trong nghiên cứu của chúng tôi, phần lớn trên siêu âm bệnh nhân đều có tổn thương lạc nội mạc trong cơ tử cung(87.1\%), trong đó tổn thương nằm ở thành sau và đáy là chủ yếu, vị trí liên quan đến các lớp cơ tử cung có tỉ lệ gần tương đồng nhau, phân bố lạc nội mạc trong cơ tử cung dạng lan tỏa chiếm $66.7 \%$, lạc nội mạc trong cơ tử cung khu trú là $14,8 \%$, u tuyến cơchiếm 18,5\%; tổn thương mức độ nặng chiếm tỷ lệ nhiều nhất là $44.5 \%$. Chúng tôi ghi nhận các dấu hiệu lạc nội mạc trong cơ tử cung thường gặp trên siêu âm bao gồm: các nang nhỏ và nhiêu đảo tăng âm trong cơ tử cung $83,9 \%$, hình rẻ quạt trong cơ tử cung $78,1 \%$, tăng tưới máu trên siêu âm Doppler màu $80,7 \%$.

Dấu hiệu trực tiếp của lạc nội mạc trong cơ tử cungtrên MRI là phát hiện các nang nhỏ trong cơ tử cung có liên quan đến các đảo của nội mạc tử cung lạc chố giãn ra.Về đặc điểm tín hiệu của tổn thương trên các chuỗi xung trong nghiên cứu của chúng tôi:Đa số tín hiệu LNMTCTC giảm đồng nhất trên $\mathrm{T} 1 \mathrm{~W}$ và hỗn hợp trên $\mathrm{T} 2 \mathrm{~W}$. Nhóm tăng trên T1W xóa mõ chiếm tỉ lệ là $38.7 \%$ liên quan đến xuất huyết. Lạc nội mạc trong cơ tử cung có bản chất giống mô tuyến thông thường nên nếu không có hiện tượng xuất huyết tín hiệu thấp trên T1W và ngược lại sẽ tăng tín hiệu nếu có xuất huyết. Trên $T 2 W$, các nang tuyến nội mạc nhỏ nằm trong cơ thường tăng tín hiệu nên LNMTC chủ yếu cóhình ảnh tín hiệu hỗn hợp. ${ }^{5,6} 6$ Lac nội mạc trong cơ tử cung không hạn chể khuếch tán trển DWI chỉ số b 1000 chiếm $93,5 \%$ và hạn chế khuếch tán chiếm $6,5 \%$.

Ngoài radấu hiệu gián tiếp chẩn đoán lạc nội mạc trong cơ tử cungtrên MRI là dày lan tỏa hoặc khu trú hay từng đoạn của vùng chuyển tiếp (junctional zone - JZ) của cơ tử cung, tạo thành vùng tín hiệu thấp ranh giới không rõ, với độ dày vùng nối $\mathrm{JZ} \geq 12 \mathrm{~mm}$ có độ nhạy và độ đặc hiệu lần lượt là $93 \%$ và $91 \%$ (theo Reinhold và $\mathrm{cs}$ ). Trong trường hợp $\mathrm{JZ}$ dày từ $8-12 \mathrm{~mm}$ thì cần xác định tiêu chí phụ trợ: tỉ lệ độ dày JZ tối đa trên độ dày của cơ tử cung đo vùng 1 vị trí > $40 \%$, sự khác biệt về độ dày tối đa và tối thiểu cả phần trước và sau tử cung $>5 \mathrm{~mm}$ (JZ chênh lệch $=J Z$ diff). Ngoài ra, tiêu chí gián tiếp khác là thấy hình ảnh tử cung to với đường viên đều đặn có độ nhạy kém $23 \%$ nhưng có độ đặc hiệu cao $98 \%{ }^{2}$ Trong nghiên cứu của chúng tôi bề dày JZ nhóm $>12 \mathrm{~mm}$ chiếm tỉ lệ nhiều nhất là $64.5 \%$ với bề dày trung bình là $22.3 \pm 17.5 \mathrm{~mm}$.

Bệnh lý vùng chậu hay đi kèm với lạc nội mạc trong cơ tử cungđược phát hiện trểnMRI bao gồmu xơ tử cung (32.3\%), nang lạc nội mạc tử cung ở phần phụ và hoặc buồng trứng (32.3\%), nang âm đạo (3.2\%), viêm phần phụ bên phải $3.2 \%$, teratoma buồng trứng phải $3.2 \%$, teratoma buồng trứng trái chiếm $3.2 \%$. Theo y văn thì tỉ lệ mắc u xơ tử cung và lạc nội mạc ở những vị trí khác ngoài tử cung trên những bệnh nhân lạc nội mạc trong cơ tử cungtăng lên từ 20$40 \%$ so với người bình thường nguyên nhân vẫn đang được nghiên cứu.

\section{KẾT LUÂ̂N}

Trong các trường hợp nghi ngờ lạc nội mạc trong cơ tử cung trên lầm sàng, siêu âm đường âm đạo và MRI là kỹ thuật hình ảnh không xâm lấn để chẩn đoán. MRI là phương pháp chẩn đoán chính xác hơn cho lạc nội mạc trong cơ tử cung, không những trong mô tả vị trí và độ lan rộng của tổn thương mà còn giúp phân biệt với u xơ tử cung trong những trường hợp khó. Đặc điểm quan trọng nhất trên MRI trong chẩn đoán là xác định độ dày của vùng nối trên $12 \mathrm{~mm}$.

\section{TÀI LIÊU THAM KHẢO}

1. Chapron $C$, Vannuccini $S$, Santulli $P$, et al. Diagnosing adenomyosis: an integrated clinical and 
imaging approach. Human Reproduction Update. 2020;26(3):392-411. doi:10.1093/humupd/dmz049

2. Gordts S, Grimbizis G, Campo R. Symptoms and classification of uterine adenomyosis, including the place of hysteroscopy in diagnosis. Fertility and Sterility. 2018;109(3):380-388.e1. doi:10.1016/ j.fertnstert.2018.01.006

3. Champaneria $\mathbf{R}$, Abedin $\mathbf{P}$, Daniels $\mathbf{J}$, Balogun M, Khan KS. Ultrasound scan and magnetic resonance imaging for the diagnosis of adenomyosis: systematic review comparing test accuracy. Acta Obstetricia et Gynecologica Scandinavica. 2010;89(11):1374-1384. doi:10.3109/00016349.2010.512061
4. Bosch TV den, Bruijn AM de, Leeuw RA de, et al. Sonographic classification and reporting system for diagnosing adenomyosis. Ultrasound in Obstetrics \& Gynecology. 2019;53(5):576-582. doi:10.1002/uog.19096

5. Chamié LP, Blasbalg $R$, Pereira RMA, Warmbrand G, Serafini PC. Findings of Pelvic Endometriosis at Transvaginal US, MR Imaging, and Laparoscopy. RadioGraphics. 2011;31(4):E77E100. doi: $10.1148 / \mathrm{rg} .314105193$

6. Agostinho $L$, Cruz $R$, Osório F, Alves J, Setúbal A, Guerra A. MRI for adenomyosis: a pictorial review. Insights Imaging. 2017;8(6):549556. doi:10.1007/s13244-017-0576-z

\section{TÌNH TRANG DINH DƯỠNG CỦA BÊNH NHÂN PARKINSON TẠI BÊ̂NH VIÊ̂N LÃO KHOA TRUNG ƯO'NG}

\section{TÓM TẮT}

Bê̂nh nhân Parkinson có nhiều triệu chứng vân động và ngoài vận động, không những làm tăng nhu cầu năng lượng mà còn giảm khả năng hấp thu các chất dinh dưỡng, năng lượng. Điều này dẫn đến bệnh nhân Parkinson dễ mắc bị suy dinh dướng. Mục tiều: Đánh giá tình trạng dinh dưỡng của bệnh nhân Parkinson tai Bênh viền Lão khoa trung ương từ tháng 7/2020 đến tháng 7/2021. Phương pháp: Tình trạng dinh dưỡng được đánh giá theo các chỉ số nhân trắc, sinh học và thang điểm đánh giá tình trạng dinh dưỡng tối thiểu MNA-SF. Kết quả: Tuổi trung bình của nhóm nghiên cứu là: 69,2 \pm 9,1tuổi, với tî lệ nữ giới chiếm $60,4 \%$. Tuổi khởi phát trung bình là: 62,8 \pm 8,0 tuổi, đa số bệnh nhân khởi phát triệu chứng bênh ở nhóm tuổi $51-70$ tuổi $(66,4 \%)$. Trong nghiên cứu của çnúng tôi, tỉ lệ bệnh nhân thiếu năng lượng trường diễn theo chỉ số chu vi vòng cánh tay và chỉ số BMI lần lượt là $34 \%$ và $27,4 \%$. Theo chỉ số sinh học, có 12 bệnh nhân $(11,3 \%)$ có vừa có tình trạng giảm albumin máu và thiếu máu. Theo thang điểm đánh giá tình trang dinh dưỡng tối thiểu MNA-SF, có $14,2 \%$ bệnh nhân bị suy dinh dưỡng và $51,9 \%$ bệnh nhân có nguy cơ suy dinh dưỡng, tổng cộng có tới $66,1 \%$ bệnh nhân có vấn đề về dinh dưỡng và cần can thiệp về dinh dưỡng. Kết luận: Trong nghiên cứu của chúng tôi, bệnh nhân Parkinson có tỉ lệ suy dinh dưỡng cao, chiếm 27,4\% khi đánh giá theo chỉ số nhân trắc và $66,1 \%$ theo thang điểm MNA-SF. Thang điểm MNA-SF có thể phát hiện sớm những thay đổi về tình trạng dinh dưỡng, tữ đó có can thiệp kịp thời về dinh dưỡng.

Tư khóa: dinh dưỡng, bệnh nhân Parkinson, thang điểm MNA-SF.

${ }^{1}$ Trường Đại học Y Hà Nọii,

${ }^{2}$ Viên dinh dướng

Chịu trách nhiệm chính: Hồ Văn Hùng

Email: hung10.hmu@gmail.com

Ngày nhận bài: 18.6.2021

Ngày phản biên khoa hoc: 17.8.2021

Ngày duyệt bài: 23.8.2021

\section{SUMMARY \\ NUTRITIONAL STATUS OF PARKINSON PATIENTS AT THE NATIONAL GERIATRICHOSPITAL}

Parkinson's patients have many motor and nonmotor symptoms, which not noly increase energy requirements but also reduce the ability to absorb nutrients and energy. This makes Parkinso's patients are more susceptible to malnutrition. Objective: This study aims to asssess the nutritional status among Parkinsion's patients at the National Geriatric Hospital between July 2020 and July 2021. Methodology: Nutritional status was evaluated bymeasuring anthropometric methods, biochemical index and MiniNutritional Assessment (MNA-SF) Short-Form Scale. Results: The average age was $69,2 \pm 9,1$ years, most of patient had onset of symptoms in the age group of $51-70$ years $(66,4 \%)$. In our study, the percentage of patients with chronic energy deficiency (CED) according to arm circumference index and BMI index was $34 \%$ and $25,5 \%$, respectively. According biochemical assessment, 12 patients $(11,3 \%)$ had bot hypoalbuminemia and anemia. According to the MNASF Scale, $14,2 \%$ patients were malnourished and $51,9 \%$ of patients were at risk of malnutrition, a total of $66,1 \%$ of patients have nutritional problems and need nutrional intervention. Conclusions: In our study, Parkinson's patients had a high rate ò malnutrition, accounting for $27,4 \%$ when assessed by anthrometric index and $66,1 \%$ according to the MNASF scale. The MNA-SF score can detect early changes in nutritional status, thereby providing timely nutritional intervention.

Keywords: Nutrition, Parkinson's disease, MNA-SF Scale

\section{I. ĐặT VẤN ĐỀ}

Bệnh Parkinson là bệnh thoái hóa thần kinh thường gặp thứ 2 sau bênh Alzheimer ở người trên 50 tuổi [1]. Năm 2017, có hơn 8,5 triệu 